\title{
Destinação de esgoto doméstico em propriedade rural unifamiliar: estudo de caso e proposição de alternativas de tratamento e reaproveitamento energético
}

\section{Domestic sewage disposal in a family rural property: case study and proposition of alternative biological treatments and energy reuse}

\author{
Elisângela Dutra Marques'; Bárbara Logullo²; Carla Eloísa Diniz Santos³ \\ ${ }^{1}$ Graduada em Engenharia Civil, Centro Universitário das Faculdades Integradas de Ourinhos, Ourinhos, \\ SP, Brasil. E-mail: eliza.dutra5@gmail.com \\ 2 Professora do Curso de Engenharia Civil, Centro Universitário das Faculdades Integradas de Ourinhos, \\ Ourinhos, SP, Brasil. E-mail:engcivilfio@gmail.com \\ ${ }^{3}$ Professora do Curso de Engenharia Ambiental, Universidade Federal do Triângulo Mineiro, Uberaba, MG, \\ Brasil. Orcid: https://orcid.org/0000-0002-5954-1026. E-mail: carla.santos@uftm.edu.br
}

RESUMO: Sistemas descentralizados, definidos pela coleta, tratamento e disposição ou reúso de águas residuárias mostram-se como alternativas interessantes para lidar com a degradação ambiental e problemática de saúde pública enfrentada em áreas rurais e comunidades urbanas isoladas. O objetivo deste trabalho foi comparar, sob o ponto de vista técnico/financeiro, duas alternativas (tanque séptico e um biodigestor Canadense) para o tratamento individualizado do esgoto doméstico produzido em uma propriedade rural, localizada no município de São Pedro do Turvo/SP. O artigo contemplou: levantamento de dados do local de estudo, levantamento dos critérios de projeto, dimensionamento e projeto em Autocad $^{\circledR}$ dos sistemas de tratamento e estudo comparativo da viabilidade técnico/econômica de implantação destes sistemas. Sob o ponto de vista técnico, ambas alternativas de tratamento demonstraram-se simples e eficazes para o tratamento individualizado do esgoto doméstico produzido na propriedade rural, desde que seguidas as normativas adequadas. Observou-se que o biodigestor Canadense apresentou menor valor total de implantação $(R \$ 911,88)$ quando comparado ao tanque séptico $(R \$ 1.314,67)$.

Palavras-chave: Tratamento descentralizado, biodigestor, biogás, tanque séptico.

ABSTRACT: Decentralized systems applied for the collection, treatment and disposal or reuse of wastewater are a promissing alternative to deal with environmental degradation and public health problems faced in rural areas and isolated urban communities. In this context, this study carried out a technical-financial comparison between two alternatives (septic tank and a Canadian biodigester) for the treatment of domestic sewage produced in a rural property, located in the municipality of São Pedro do Turvo / SP. The experimental design of this investigation included: study of local data, analysis of project requirements, calculations and design in Autocad ${ }^{\mathrm{TM}}$ and a comparative study of technical/economic feasibility of both systems. From a technical point of view, both alternatives are simple and easy to execute, as applied regulations are followed. The Canadian biodigester showed a lower implantation cust $(R \$ 911,88)$ when compared to the septic tank $(R \$ 1.314,67)$.

Keywords: Decentralized treatments, biodigester, biogas, septic tank. 
Revista Brasileira de Ciência, Tecnologia e Inovação

\section{INTRODUÇÃO}

A falta de saneamento básico ainda é uma das grandes causas de mortes por doenças de veiculação hídrica e pela degradação do meio ambiente em diversos países em desenvolvimento. Uma avaliação dos serviços de saneamento básico no Brasil, mostra que o esgotamento sanitário é a vertente que apresenta menor cobertura municipal (LANDAU e MOURA, 2016; TONETTI et al., 2018). De acordo com o Diagnóstico de Serviços de Água e Esgoto realizado pela Secretaria Nacional de Saneamento (SNS), em 2018, o índice de atendimento urbano com rede de esgotos no Brasil foi de 53.2\% (SNS, 2019). As principais justificativas para tal cenário são o crescimento desordenado das cidades e a falta de planejamento urbano pelos órgãos públicos (FUNASA, 2015).

$\mathrm{Em}$ áreas rurais e comunidades urbanas isoladas, o acesso às infraestruturas de saneamento básico é praticamente inexistente, seja pela distância das localidades, falta de informação ou simples descaso das políticas públicas, já que atualmente existem tecnologias descentralizadas que possibilitam o tratamento do esgoto doméstico (TONETTI et al., 2018).

Segundo levantamento do Instituto Brasileiro de Geografia e Estatística (IBGE), 8\% dos domicílios rurais pesquisados têm acesso à rede coletora de esgoto e $13 \%$ não possuem nenhum tipo de sistema de tratamento de esgoto (IBGE, 2013). Entre os domicílios que possuem algum tipo de tratamento, 58\% necessitam de imediata melhora, uma vez que nessas propriedades dispõem-se de fossas negras, ou o lançamento do esgoto é realizado em valas, corpos d'água e outras localidades (IBGE, 2013). Atualmente, observa-se uma tendência mundial no que diz respeito à proposição de tecnologias descentralizadas de tratamento de esgoto sanitário, as quais têm como vantagem a redução da extensão dos interceptores principais. Tais canalizações são responsáveis por receber e transportar o esgoto sanitário coletado até as Estações de Tratamento de Esgotos (ETEs) (METCALF \& EDY, 2018). Dentre as alternativas descentralizadas de tratamento de esgoto doméstico, a implantação de tanques sépticos ou biodigestores apresenta-se como uma opção economicamente viável para o atendimento de moradores das zonas rurais e comunidades isoladas (TONETTI et al., 2018).

A utilização destes sistemas de tratamentos em áreas rurais e comunidades isoladas colabora para a universalização do saneamento básico, propicia melhoria na qualidade de vida da população e atua na conservação dos recursos naturais (água, solo, fauna e flora). Além disso, na esfera de políticas públicas, permite a redução de ocorrência de doenças de veiculação hídrica e possibilita um adequado gerenciamento dos recursos hídricos (FUNASA, 2015). O presente trabalho realizou uma comparação técnico-econômica entre duas alternativas (tanque séptico e um biodigestor Canadense) para o tratamento individualizado do esgoto doméstico produzido em uma propriedade rural, localizada no município de São Pedro do Turvo/SP.

\section{REFERENCIAL TEÓRICO}

Esgoto doméstico é definido como o resíduo líquido proveniente de atividades higiênicas e/ou de limpeza (ABNT, 1993). Os esgotos domésticos contém, aproximadamente, $99,9 \%$ de água, sendo o volume restante composto de sólidos orgânicos e inorgânicos, bem como microrganismos, fungos, protozoários, helmintos e vírus (CONTERATO, 2018). 
Revista Brasileira de Ciência, Tecnologia e Inovação

Como mencionado anteriormente, o tanque séptico é considerado uma altenativa satisfatória para o tratamento de esgoto doméstico, sendo indicado em substituição às fossas negras, comumente adotas em áreas de vulnerabilidade (TONETTI et al., 2018). A fossa negra, também conhecida como fossa absorvente, rudimentar ou caipira, constitui-se de um poço ou buraco feito no solo para a recepção do esgoto doméstico. Pelo fato de não contar com nenhum tipo de impermeabilização, permite a infiltração da fração líquida no solo, resultando em riscos de contaminação do solo e das águas subterrâneas (FUNASA, 2015; TONETTI et al., 2018).

Os tanques sépticos permitem a retenção de sólidos sedimentáveis e flutuantes contidos no esgoto e a remoção parcial da matéria orgânica (ABNT, 1993), caracterizandose como uma unidade de tratamento primário e secundário. A NBR 7.229/1993 - Projeto, operação e construção de sistemas de tanques sépticos, fixa as condições exigíveis para o projeto, construção e operação destes sistemas, incluindo tratamento e disposição de efluentes e lodo sedimentado (ABNT, 1993). Como complemento existe também a NBR 13.969/1997 - Tanques sépticos: Unidades de tratamento complementar e disposição final de efluentes, que apresenta alternativas de unidades de tratamento complementar e disposição final dos efluentes líquidos oriundos do tanque séptico. Com relação ao lodo e escuma produzido no tanque séptico, a NBR 7.229/1993 prevê a realização de limpeza dos tanques sépticos em intervalos de 1 a 5 anos (ABNT, 1993).

Segundo Tonetti et al. (2018) a remoção do lodo deve ser feita com cuidado, evitando-se o contato entre as pessoas e o lodo removido. Além disso, aproximadamente $10 \%$ do volume de lodo deve permanecer no tanque séptico, com o objetivo de não prejudicar o tratamento após a limpeza (TONETTI et al., 2018). O lodo coletado pode ser disposto em leitos de secagem, conforme critérios expostos na NBR 12.209/2011 Elaboração de projetos hidráulicos-sanitários de estações de tratamento de esgotos sanitário (ABNT, 2011). Após sua estabilização pode ser utilizado como composto agrícola. Entretanto, ainda não existe uma legislação específica que regule o gerenciamento de lodo de sistemas isolados para aplicação agrícola (TONETTI et al., 2018).

Outra alternativa que pode ser implantada para tratamento de esgoto doméstico de áreas rurais ou comunidades urbanas isoladas é o biodigestor. Um biodigestor consiste da associação de uma câmara fechada e um gasômetro. Na câmara fechada se dá a decomposição de matéria orgânica (em suspensão ou dissolvida) por bactérias anaeróbias (DEGANUTTI et al., 2002). Este processo ocorre na ausência de oxigênio e é caracterizado por um conjunto de microrganismos capazes de converter a matéria orgânica em metano $\left(\mathrm{CH}_{4}\right)$, dióxido de carbono $\left(\mathrm{CO}_{2}\right)$, sulfeto de hidrogênio $\left(\mathrm{H}_{2} \mathrm{~S}\right)$ e outros compostos (CONTERATO, 2018). Há diversos modelos de biodigestores, os quais são classificados quando ao tipo de carregamento de esgoto (ANDRADE et al., 2002). O modelo em batelada, normalmente aplicado para biodegradar biomassa, recebe carga total de matéria orgânica a ser tratada a cada 28 dias (ANDRADE et al., 2002). Já outras configurações necessitam ser alimentadas continuamente (geralmente uma vez ao dia). Como exemplos podem-se listar os biodigestores indiano, chinês e o canadense, também conhecido como biodigestor de lagoa coberta (BLC) (ANDRADE et al., 2002). Segundo Tonetti et al. (2018), o biodigestor permite o tratamento tanto do esgoto doméstico, como de outros resíduos produzidos na propriedade, tais como: esterco, sobras de alimentos, podas de árvores, entre outros. A partir da decomposição da matéria orgânica, além do efluente líquido final, biogás também é produzido. $\mathrm{O}$ biogás é rico em $\mathrm{CH}_{4}$, fato que viabiliza seu uso como fonte energética para iluminação, aquecimento e uso direto como gás de cozinha. $\mathrm{O}$ uso de 
biodigestor também demanda a retirada do lodo no período de 2 a 4 anos, seguindo os mesmos critérios definidos para a limpeza da fossa séptica (TONETTI et al., 2018).

A NBR 8.160/1999 recomenda instalação de caixa de gordura na saída da cozinha, precedendo as unidades de tratamento biológico (tanque séptico ou biodigestor), visando a retenção de gordura presente no esgoto doméstico para que esse material não danifique ou interrompa o fluxo nas tubulações. Para disposição final. a NBR 13.969/1997, recomenda que seja feita um tratamento complementar na saída do dispositivos e só então a disposição final do efluente tratado.

\section{PROCEDIMENTOS METODOLÓGICOS}

O delineamento experimental deste trabalho contemplou as etapas de levantamento de dados da área de estudo, levantamento dos critérios de projeto pertinentes, dimensionamento dos sistemas de tratamento, projeto dos sistemas em AutoCad ${ }^{\circledR}$ (versão 2016) e estudo da viabilidade técnico/econômica de implantação destes sistemas. A Figura 1 retrata, de maneira simplificada, as etapas executadas no presente estudo.

Figura1. Fluxograma experimental do trabalho.

\begin{tabular}{|c|c|c|}
\hline $\begin{array}{c}\text { Caracterização } \\
\text { da propriedade } \\
\text { rural }\end{array}$ & $\begin{array}{l}\text { Levantamento } \\
\text { dos critérios } \\
\text { técnicos de } \\
\text { projeto }\end{array}$ & $\begin{array}{l}\text { Dimensionamento dos } \\
\text { sistemas de tratamento: } \\
\text {-fossa séptica } \\
\text { - biodigestor }\end{array}$ \\
\hline 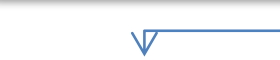 & & \\
\hline $\begin{array}{c}\text { Projetos no } \\
\text { software } \\
\text { AutoCad }^{\circledR}\end{array}$ & $\begin{array}{c}\text { Levantamento } \\
\text { dos custos de } \\
\text { Projeto e } \\
\text { Implantação }\end{array}$ & $\begin{array}{c}\text { Estudo comparativo } \\
\text { (técnico/econômico) } \\
\text { dos sistemas } \\
\text { dimensionados }\end{array}$ \\
\hline
\end{tabular}

\section{Caracterização da propriedade rural}

São Pedro do Turvo é um município situado no interior do Estado de São Paulo, localizado a 39,8 km cidade de Ourinhos, cujas principais atividades econômicas são a agricultura e a pecuária. Segundo dados do IBGE, em 2010 a população total do município de São Pedro do Turvo era de 7.198 habitantes. Deste número total, 2048 moradores vivem na zona rural. A média geral de moradores por domicílio (independente de ser nas zonas urbana ou rural) corresponde a 3,06 moradores (IBGE, 2010).

\section{Critérios e parâmetros de dimensionamento dos sistemas de tratamento}

Para dimensionamento do tanque séptico adotaram-se as diretrizes dispostas nas seguintes normas técnicas da Associação Brasileira de Normas Técnicas (ABNT):

- NBR 7.229/1993 - Projeto, construção e operação de sistema de tanques sépticos;

- NBR 5.626/1996 - Instalações Prediais de agua fria - Procedimento;

- NBR 13.969/1997 - Tanques sépticos, unidades de tratamento complementar; e disposição final de efluentes líquidos - projeto e execução;

- NBR 8.160/1999 - Instalações Prediais de esgoto sanitário - Procedimento. 
Já o dimensionamento do projeto do biodigestor levou-se em consideração os seguintes aspectos:

a) local de implantação - local com boa incidência de sol, para auxiliar no processo de fermentação na câmara do biodigestor;

b) volume diário de dejetos dos animais existentes na propriedade rural;

c) volume diário de esgoto doméstico;

d) modelo do biodigestor a ser utilizado.

$\mathrm{Na}$ sequência serão brevemente apresentadas as etapas aplicadas ao dimensionamento das unidades de tratamento estudadas (fossa séptica e biodigestor). Nos dois casos, adotou-se população de 3 habitantes por residência, conforme os dados censitários do município de São Pedro do Turvo/SP (IBGE, 2010).

\section{Dimensionamento do tanque séptico}

De acordo com a NBR 7229/1993, inicia-se o dimensionamento do tanque séptico pelo cálculo do volume útil do sistema (Equação 1). Na Equação 1 adotaram-se os parâmetros de projeto expostos na Tabela 1, obtidos a partir das recomendações da NBR 7229/1993.

$V=1000+N\left(C \times T+K \times L_{F}\right)$

em que: $V$ é o volume útil tanque séptico (L); $N$ é o número de pessoas contribuintes (hab); $C$ é a taxa de contribuição de esgoto per capita $\left(\mathrm{L} . h a b^{-1} \cdot \mathrm{dia}^{-1}\right) ; T$ é o período de detenção dos despejos; $K$ é a taxa de acumulação do lodo digerido (dias) e $L_{F}$ é a taxa de contribuição do lodo fresco $\left(\right.$ L.hab ${ }^{-1}$.dia-1 ${ }^{-1}$.

Considerando um tanque de formato prismático retangular, a área superficial $\left(A_{B}\right)$ pode ser calculada pelas Equações 2 e 3:

$A_{B}=L \times B$

$V=A_{B} \times h$

em que: $L$ é a largura do tanque séptico $(\mathrm{m}) ; B$ é o comprimento do tanque séptico $(\mathrm{m})$ e $h$ é a profundidade do tanque séptico $(\mathrm{m})$.

No tópico 5.9 da NBR 7229/1993, a largura interna mínima é de $80 \mathrm{~cm}$, a relação comprimento/largura mínima para tanques prismáticos retangulares é de 2:1 e a máxima é de $4: 1$.

Tabela 1 - Critérios de projeto para dimensionamento do tanque séptico de acordo com a NBR 7229/1993.

\begin{tabular}{ccc}
\hline Parâmetro & Símbolo & Valor adotado \\
\hline Número de pessoas contribuintes & $N$ & 3 habitantes \\
Contribuição de despejos & $C$ & $100{\mathrm{~L} . \mathrm{hab}^{-1} \cdot \mathrm{dia}^{-1}}^{\text {dia }}$ \\
Período de detenção & $T$ & $105 \mathrm{dia}^{-1}$ \\
Taxa de acumulação do lodo digerido & $K$ & $1 \mathrm{~L} \cdot \mathrm{hab}^{-1} \cdot \mathrm{dia}^{-1}$ \\
Contribuição do lodo fresco & $L_{F}$ & $2 / 1$ \\
Relação comprimento/largura mínima & $L / B$ & $0,80 \mathrm{~m}$ \\
Largura interna mínima & $L$ & $1,20 \mathrm{~m}$ \\
\hline Profundidade mínima & $h$ & \\
\hline
\end{tabular}




\section{Dimensionamento do biodigestor canadense}

O biodigestor a ser adotado neste trabalho é tipo canadense, o qual consiste de tanque escavado no solo, impermeabilizado e coberto com material geossintético (PVC, PEAD, etc.) (KUNZ; STEINMETZ; AMARAL, 2019). A geometria deste tipo de biodigestor é de base retangular de seção trapezoidal com inclinação do talude variável, dependendo das características do solo. O biodigestor canadense é um sistema de baixo nível tecnológico e que apresenta fácil construção e operação (RIBEIRO, 2011; KUNZ; STEINMETZ; AMARAL, 2019).

Para estimar as dimensões do biodigestor foi necessário, primeiramente, calcular a vazão de esgoto ou volume diário dada pela (Equação 4) e volume útil (Equação 5) relacionado à carga diária de efluente a ser tratado. Na Equação 4, o tempo de retenção hidráulica $(\mathrm{TRH})$ representa o tempo médio em que o substrato permanece no interior do biodigestor, visando a produção de biogás (OLIVER et al., 2008; KUNZ; STEINMETZ; AMARAL, 2019). Segundo Oliver et al. (2008), o TRH pode variar de 30 a 45 dias, dependendo da carga orgânica adicionada ao biodigestor.

$V_{C}=P \times q \times C$

em que: $V_{C}$ é o volume diário $\left(\mathrm{m}^{3} \cdot \mathrm{dia}^{-1}\right) ; q=$ representa o consumo per capita de água $\left(\right.$ L.hab $^{-1}$.dia-1 $) ; P=$ representa a população da propriedade; $C=0$ coeficiente de retorno (adimensional, adota-se $=0,8$ conforme Norma ABNT no7229/1993).

$V_{B}=V_{C} \times T R H$

em que: $V_{B}$ é o volume útil do biodigestor $\left(\mathrm{m}^{3}\right)$; $V_{C}$ é o volume de carga diária de efluente a ser tratada (esgoto doméstico) $\left(\mathrm{m}^{3}\right.$.dia ${ }^{-1}$ ) e TRH é o tempo de retenção hidráulico (dias).

$\mathrm{Na}$ Tabela 2, encontram-se listados parametros usados para dimensionamento do biodigestor:

Tabela 2 - Critérios de projeto para dimensionamento do biodigestor.

\begin{tabular}{ccc}
\hline Parâmetro & Símbolo & Valor adotado \\
\hline População da propriedade & $P$ & 3 habitantes \\
Consumo per capita & $q$ & $100 \mathrm{~L}_{\text {.hab }}^{-1} \cdot$ dia $^{-1}$ \\
Tempo de retenção hidráulico & $T R H$ & 32 dias $^{-1}$ \\
Coeficiente de retorno & $C$ & 0,80 \\
\hline
\end{tabular}

Na sequência, o volume útil do biodigestor foi utilizado na estimativa das dimensões reais do biodigestor (RIBEIRO, 2011). Para cálculo das dimensões do biodigestor, utilizaram-se as equações dispostas no Quadro 1.

Para cálculo da demanda de biogás e geração de energia, a Tabela 3 representa para alguns animais, a produção média de dejetos por dia, e seu potencial de geração de biogás e o equivalente em energia elétrica ( $\mathrm{kWh}$ ).

Na Tabela 3 pode-se verificar exemplos os índices de produção de biogás, demanda energética (uso como gás de cozinha (GLP) e produção de energia elétrica) de acordo com a origem e volume de rejeitos produzidos diariamente.

Para esgoto doméstico serão utilizados apenas dejetos humanos, para avaliar o potencial de reaproveitamento energético na propriedade rural de estudo. 
Quadro 1 - Equações necessárias para o dimensionamento do biodigestor canadense.

\begin{tabular}{|c|c|c|}
\hline Equações & № & Descrição \\
\hline$P=C=2 \pi r$ & (6) & $\begin{array}{l}P=\text { Perímetro total transversal (campana mais fossa) }(\mathrm{m}) \\
C=\text { Circunferência da campana } \\
\mathrm{r}=\text { raio da campana }(\mathrm{m})\end{array}$ \\
\hline$A_{\%}=0,621 p^{2}-0,04 p+0,352$ & (7) & $\begin{array}{l}A_{\%}=\text { Porcentagem de perímetro transversal destinado ao arco. } \\
p=\text { Proporção da fase gasosa desejada }(p \leq 0,4)\end{array}$ \\
\hline$b=-\left(\frac{1}{3} A_{\%}+\frac{1}{3}\right) \times P$ & $(8)$ & $\begin{array}{l}b=\text { Lateral, base ou largura menor da fossa }(\mathrm{m}) \\
P=\text { Perímetro total transversal }(\mathrm{m})\end{array}$ \\
\hline$a=1,618 b$ & (9) & $\begin{array}{l}a=\text { largura maior da fossa }(\mathrm{m}) \\
b=\text { Lateral, base ou largura menor da fossa }(\mathrm{m})\end{array}$ \\
\hline$h=0,951 b$ & (10) & $\begin{array}{l}h=\text { profundidade da fossa }(\mathrm{m}) \\
b=\text { Lateral, base ou largura menor da fossa }(\mathrm{m})\end{array}$ \\
\hline $\begin{aligned} & A_{f}=0,4755(a+b) \times b \\
& A_{f}=0,4755(a+b) \times b\end{aligned}$ & $(11)$ & $\begin{array}{l}A_{f}=\text { Área transversal da fossa }\left(\mathrm{m}^{2}\right) \\
a=\text { largura maior da fossa }(\mathrm{m}) \\
b=\text { Lateral, base ou largura menor da fossa }(\mathrm{m})\end{array}$ \\
\hline$A_{t}=\frac{A_{f}}{1-p}$ & $(12)$ & $\begin{array}{l}A_{t}=\text { Área total transversal ou área transversal da fossa mais } \\
\text { área transversal da campana }\left(\mathrm{m}^{2}\right) \\
p=\text { Proporção da fase gasosa desejada }\end{array}$ \\
\hline$A_{g}=A_{t}-A_{f}$ & (13) & $\begin{array}{l}A_{g}=\text { Área transversal da campana ou área destinada para o } \\
\text { armazenamento do biogás }\left(\mathrm{m}^{2}\right)\end{array}$ \\
\hline$V_{T}=A_{t} \times L$ & $(14)$ & $\begin{array}{l}V_{T}=\text { Volume total do biodigestor (campana mais fossa) }\left(\mathrm{m}^{3}\right) \\
L=\text { Comprimento do biodigestor (valor inicial adotado) }(\mathrm{m})\end{array}$ \\
\hline$V_{f}=A_{f} \times L$ & $(15)$ & $\begin{array}{l}V_{f}=\text { Volume total da fossa }\left(\mathrm{m}^{3}\right) \\
L=\text { Comprimento do biodigestor (valor inicial adotado) }(\mathrm{m})\end{array}$ \\
\hline$V_{g}=A_{g} \times L$ & $(16)$ & $\begin{array}{l}V_{g}=\text { Volume total do gás }\left(\mathrm{m}^{3}\right) \\
L=\text { Comprimento do biodigestor (valor inicial adotado) }(\mathrm{m})\end{array}$ \\
\hline
\end{tabular}

Fonte: Adaptado de Ribeiro (2011).

Tabela 3 - Índices de produção de biogás, gás de cozinha e energia elétrica, de acordo com a origem do rejeito.

\begin{tabular}{|c|c|c|c|c|}
\hline Tipo & $\begin{array}{l}\text { Volume diário } \\
\text { de rejeitos } \\
\left(\mathrm{kg} \cdot \mathrm{dia}^{-1}\right)\end{array}$ & $\begin{array}{l}\text { Produção de biogás } \\
\left(\mathrm{m}^{3} \text {. dia }{ }^{-1} \text { animal }{ }^{-1}\right)\end{array}$ & $\begin{array}{l}\text { Produção de } \\
\text { GLP } \\
\text { (kg.dia-1) }\end{array}$ & $\begin{array}{c}\text { Produção de energia } \\
\text { elétrica } \\
\left.\text { (Kwh.dia }{ }^{-1}\right)\end{array}$ \\
\hline Humano & 0,25 & 0,01 & 0 & 0,01 \\
\hline Galinha & 0,18 & 0,01 & 0 & 0,01 \\
\hline Caprinos/ovinos & 0,50 & 0,07 & 0,14 & 0,07 \\
\hline Suínos & 16,00 & 0,08 & 0,03 & 0,08 \\
\hline Vaca leiteira & 25,00 & 0,54 & 0 & 0,54 \\
\hline Cachorro & 0,33 & 0,03 & 0,01 & 0,03 \\
\hline
\end{tabular}

Fonte: Adaptado de BGS Equipamentos (2018) e Ribeiro (2011).

\section{RESULTADOS E DISCUSSÃO}

\section{Dimensionamento do tanque séptico}

A partir da Equação 1, estimou-se que o volume útil ( $V$ ) do tanque séptico foi de 1,615 $\mathrm{m}^{3}$ (Tabela 4). Para este projeto, adotou-se uma câmara de tratamento com formato prismático retangular, a qual, segundo a NBR 7229 (ABNT, 1993), é suficiente para atender até 30 pessoas, com uso das Equações 2 e 3 e utilizando os valores mínimos que a norma 
preconiza, pode-se estimar os valores Área Base: $(L \times B)=0,80 \times 1,60=1,28 \mathrm{~m}^{2}$ e utilizando a profundidade mínima $(A B N T 7229)=1,20 \mathrm{~m}$, tem-se que $V=A B \times H, V($ volume útil) $=$ $1,615 \mathrm{~m}^{3}$, para volume estimado de $1.615 \mathrm{~L}=1,28 \times H$, onde $H=1,26 \mathrm{~m}$, adotou-se $H=$ $1,30 \mathrm{~m}$ (Profundidade).

Tabela 4 - Dimensões do tanque séptico dimensionado para o tratamento do esgoto doméstico produzido na propriedade rural de estudo.

\begin{tabular}{cc|}
\hline Parâmetro & Dimensão \\
\hline Volume útil & $1,615 \mathrm{~m}^{3}$ \\
Profundidade adotada & $1,300 \mathrm{~m}$ \\
Largura interna & $0,800 \mathrm{~m}$ \\
Comprimento & $1,600 \mathrm{~m}$ \\
\hline
\end{tabular}

As Figuras 2 e 3 ilustram a planta e o detalhe de corte do tanque séptico projetado, obtidas com auxílio do AutoCad ${ }^{\circledR}$.

Figura 2 - Planta do tanque séptico com indicação das dimensões obtidas.

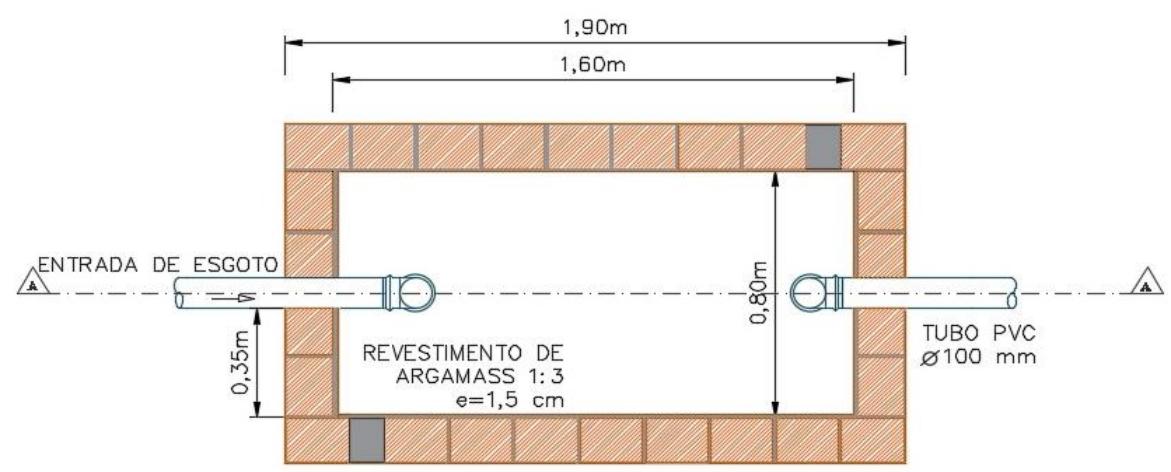

Figura 3 - Detalhe de corte transversal do tanque séptico.

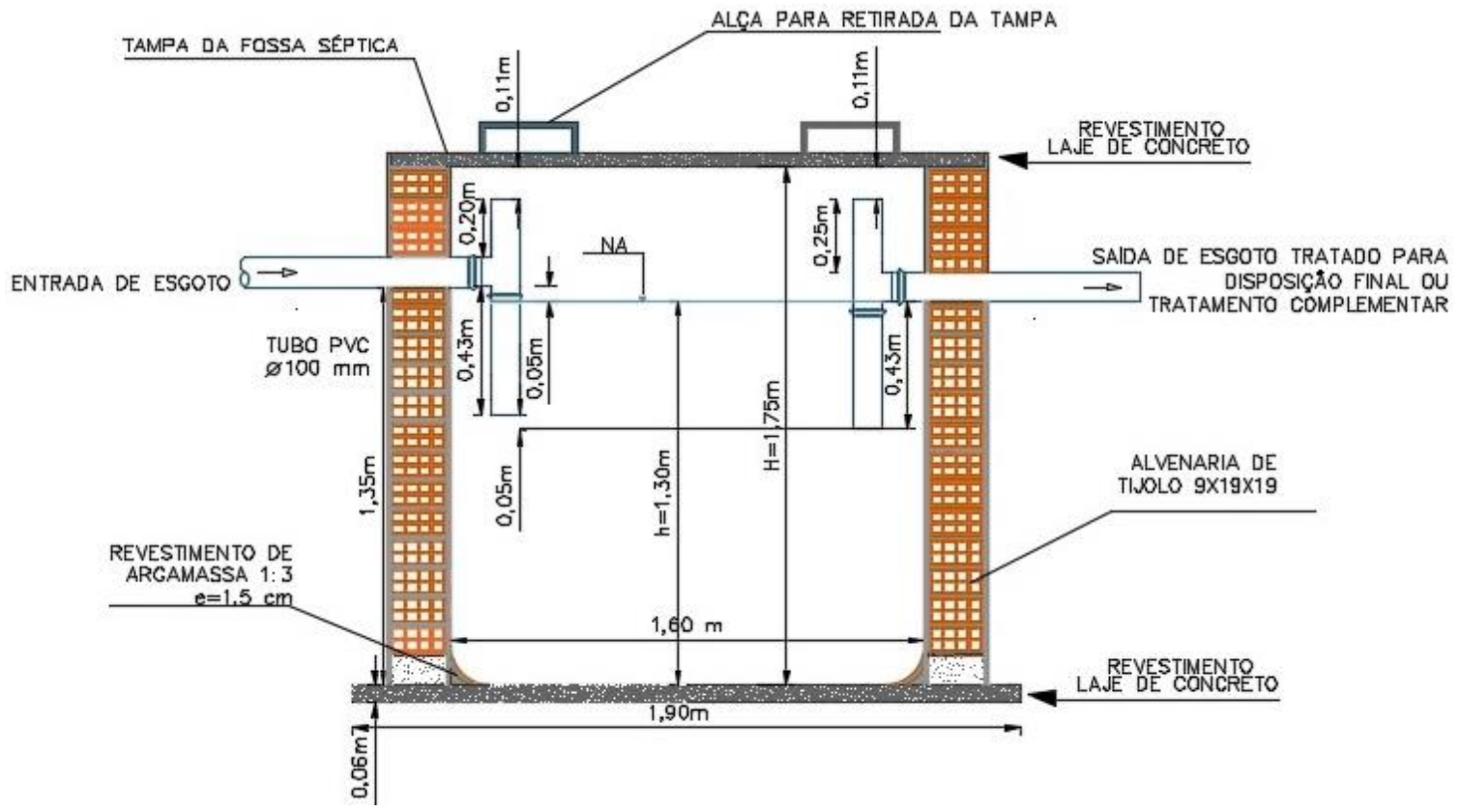




\section{Dimensionamento do biodigestor}

O dimensionamento do biodigestor foi iniciado a partir da estimativa da vazão total de esgoto doméstico e volume ùtil do biodigestor. Na Tabela 5 encontram-se valores estimados, considerando TRH de 32 dias tem-se:

Tabela 5 - Parâmetros relacionados ao cálculo das dimensões do biodigestor.

\begin{tabular}{cc}
\hline Parâmetro & Valor \\
\hline Volume útil do Biodigestor $\left(V_{B}\right)$ & $7,68 \mathrm{~m}^{3}$ \\
Volume diário de esgoto doméstico $\left(V_{C}\right)$ & $0,24 \mathrm{~m}^{3} \cdot$ dia $^{-1}$ \\
\hline
\end{tabular}

Vale ressaltar que, para otimizar a produção de biogás, Ribeiro (2011) recomenda que a fase gasosa ocupe, no máximo, $40 \%$ do volume do biodigestor. Sendo assim, os parâmetros $L, p$ e $R$ (Tabela 6) estão relacionados ao volume estimado do biodigestor ( $V_{B}$ $\left.=7,68 \mathrm{~m}^{3}\right)$ e seu valores foram estimados a partir do equacionamento disponível no Quadro 1 e com auxílio de planilha no Excel.

Tabela 6 - Parâmetros iniciais para dimensionamento do biodigestor.

\begin{tabular}{cclc}
\hline $\begin{array}{c}\text { Volume diário } \\
\left(\mathrm{m}^{3} \cdot \text { dia }^{-1}\right)\end{array}$ & $\begin{array}{c}\text { Volume do } \\
\text { biodigestor }\left(\mathrm{m}^{3}\right)\end{array}$ & Dimensões adotadas $(\mathrm{m})$ & $\begin{array}{c}\text { Caixa de } \\
\text { compensação }(\mathrm{m})\end{array}$ \\
\hline 0,24 & 7,68 & $\begin{array}{l}\text { Raio }(R): 1,30 \mathrm{~m} \\
\text { Comprimento }(L): 1,65 \mathrm{~m} \\
p=0,2 \text { (fator) }\end{array}$ & $0,90 \times 1,00 \times 0,50$ \\
\hline
\end{tabular}

Como mencionado no tópico de Referencial Teórico, a NBR 8160/1999 recomenda a instalação de caixa de gordura na saída da cozinha, precedendo o biodigestor. Tal recomendação visa a remoção e retenção de gordura presente no esgoto doméstico para que esse material não danifique ou interrompa o fluxo nas tubulações. A NBR 8160/1999, recomenda que, para apenas uma cozinha contribuinte, uma única caixa de gordura simples é suficiente.

Tal dispositivo é dividido em duas câmaras, uma receptora e outra vertedoura, separadas por septo fixo. A figura 4 retrata a planta baixa e o corte transversal de uma caixa de gordura cilíndrica simples. Dimensões mínimas foram indicadas na Figura 4, considerando-se a contribuição de uma única pia, de acordo com as recomendações da NBR 8160/1999.

A Tabela 7 apresenta as dimensões encontradas para o biodigestor canadense. A Figura 5 retrata o corte transversal do biodigestor, caixa de compensação, juntamente com as dimensões principais. 


\section{RB \\ Revista Brasileira de Ciência, Tecnologia e Inovação}

Figura 4 - Planta baixa (a) e corte (b) de caixa de gordura simples e seus detalhes construtivos.

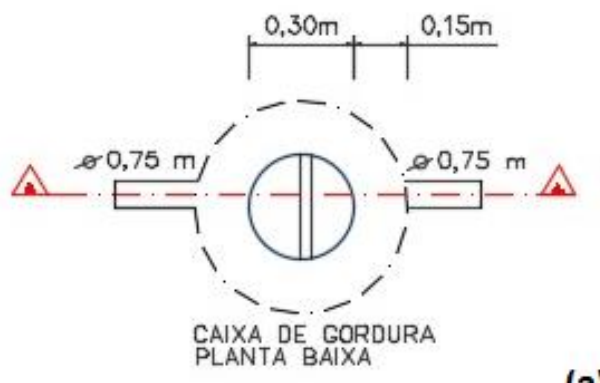

(a)

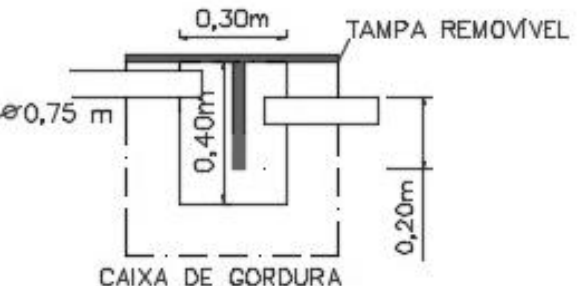

CAIXA DE (b)

Tabela 7 - Dimensões do biodigestor canadense dimensionado para o tratamento dos rejeitos produzidos na propriedade rural de estudo.

\begin{tabular}{crc}
\hline Símbolo & Parâmetro & Dimensão \\
\hline$P$ & Perímetro total (campana + fossa) & $8,16 \mathrm{~m}$ \\
$A \%$ & Porcentagem do perímetro transversal destinado ao arco & $0,36 \mathrm{~m}^{3}$ \\
$R$ & Raio de Campana & $1,30 \mathrm{~m}$ \\
$p$ & Proporção da fase gasosa & $20 \%$ \\
$b$ & Lateral, base ou largura menor da fossa & $1,73 \mathrm{~m}$ \\
$a$ & Largura maior da fossa & $2,80 \mathrm{~m}$ \\
$h$ & Profundidade da fossa & $1,64 \mathrm{~m}$ \\
$A_{f}$ & Área transversal da fossa & $3,72 \mathrm{~m}^{2}$ \\
$A_{t}$ & Área total (campana + fossa) & $4,65 \mathrm{~m}^{2}$ \\
$A_{g}$ & Área destinada ao biogás & $0,93 \mathrm{~m}^{2}$ \\
$V_{t}$ & Volume total do biodigestor (campana + fossa) & $7,68 \mathrm{~m}^{3}$ \\
$V_{f}$ & Volume total da fossa & $6,14 \mathrm{~m}^{3}$ \\
$V_{g}$ & Volume total do biogás & $1,53 \mathrm{~m}^{3}$ \\
$L$ & Comprimento do Biodigestor & $1,65 \mathrm{~m}^{3}$ \\
\hline
\end{tabular}

Figura 5 - Corte transversal do biodigestor canadense dimensionado e detalhes construtivos.

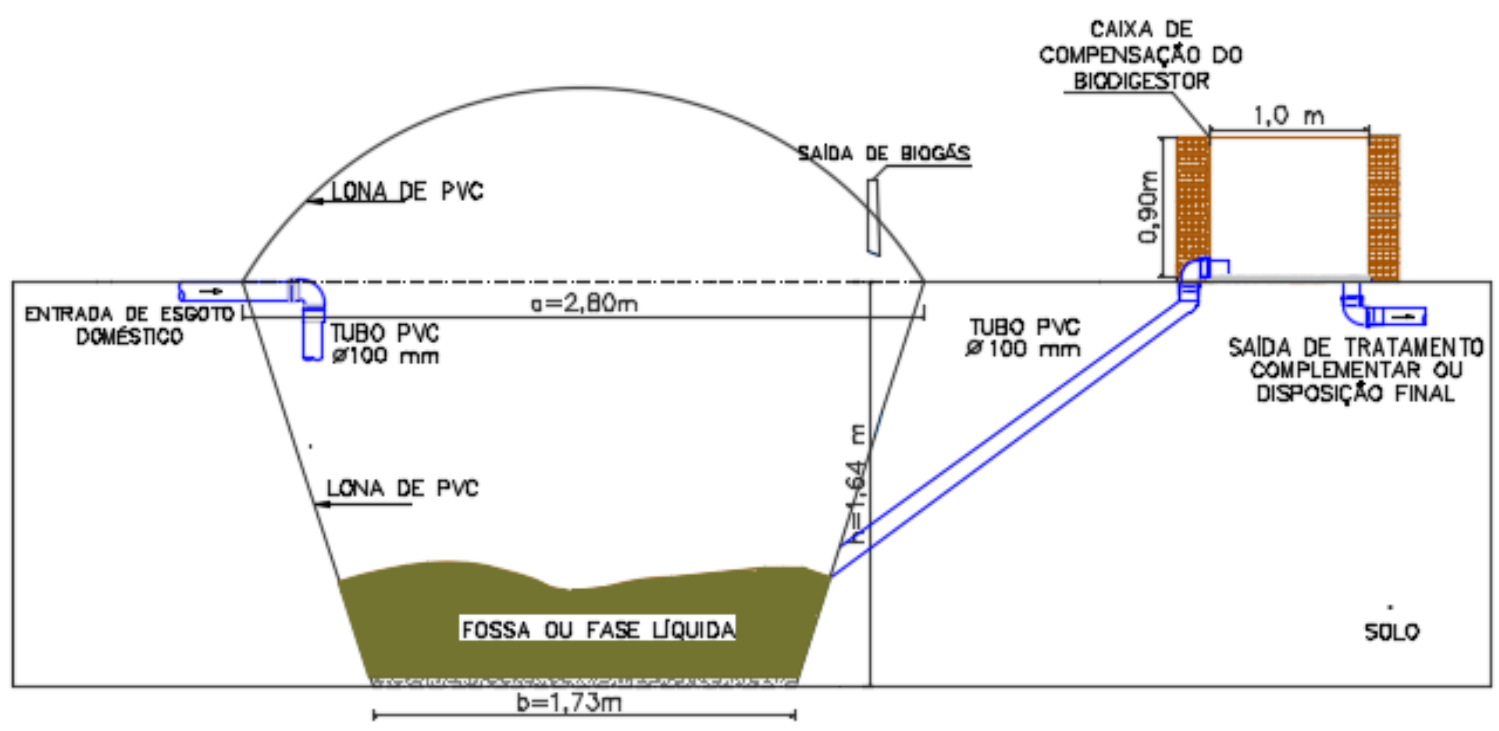


Revista Brasileira de Ciência, Tecnologia e Inovação

Ambas as alternativas de tratamento abordadas neste trabalho demandam uma unidade de pós-tratamento dos efluentes. Existem várias alternativas, as quais divergem entre si, de modo geral, de acordo com as faixas de remoção da matéria orgânica desejadas (NBR 13969/1997; TONETTI et al., 2018). Dentre as alternativas de tratamento complementar dispostas na NBR $13969 / 1997$ pode-se citar os sistemas alagados construídos (wetlands), filtros anaeróbios e filtros de areia. Além disso, no caso específico do biodigestor, o destino do esgoto tratado deve ser avaliado criteriosamente, pois de acordo com a qualidade, em alguns casos o mesmo pode ser utilizado como biofertilizante em pomares e pastos (TONETTI et al., 2018).

Recomenda-se o filtro de areia como unidade de tratamento complementar, tanto para o efluente final obtido na fossa séptica quanto no biodigestor canadense. No filtro de areia ocorre a passagem do efluente através de camadas de areia seguida por outros materiais filtrantes, como brita, pedrisco ou seixo rolado, resultando em um polimento do efluente tratado previamente, tanto sob o ponto de vista físico (retenção de partículas), quanto bioquímico (oxidação de compostos poluentes pela ação de microrganismos) (ABNT,1999; TONETTI et al., 2018). O filtro de areia pode ser construído de anéis de concreto, alvenaria, bombonas plásticas, caixas d'água, ou outro material impermeável. $A$ profundidade mínima deve ser de $1 \mathrm{~m}$ e o sistema não requer manutenção complexa. Em unidades unifamiliares, a NBR13969/1997 recomenda que seja feita a retirada da areia e outros materiais do filtro a cada 4 meses. Em seguida, esses materiais devems er dispostos ao sol para secagem e posterior reutilização. A Figura 6 mostra corte transversal e detalhes de filtro de areia dimensionado como unidade de tratamento complementar neste estudo.

A disposição final do efluente obtido, tanto pelo uso da fossa séptica quanto pela adoção do biodigestor, pode ser realizada em corpos d' água, lagos ou rios, desde que a qualidade desse efluente esteja de acordo com a classificação dos corpos hídricos recomendada nas resoluções do Conselho Nacional de Meio Ambiente (CONAMA) 357/2005 e 430/2011. Além disso, recomenda-se o reúso em jardins (exceto irrigação de pomares e hortaliças) ou lavagem de calçadas.

Figura 6 - Planta baixa (a) e corte do filtro de areia (b) para tratamento complementar de esgoto doméstico produzido na propriedade rural de estudo.

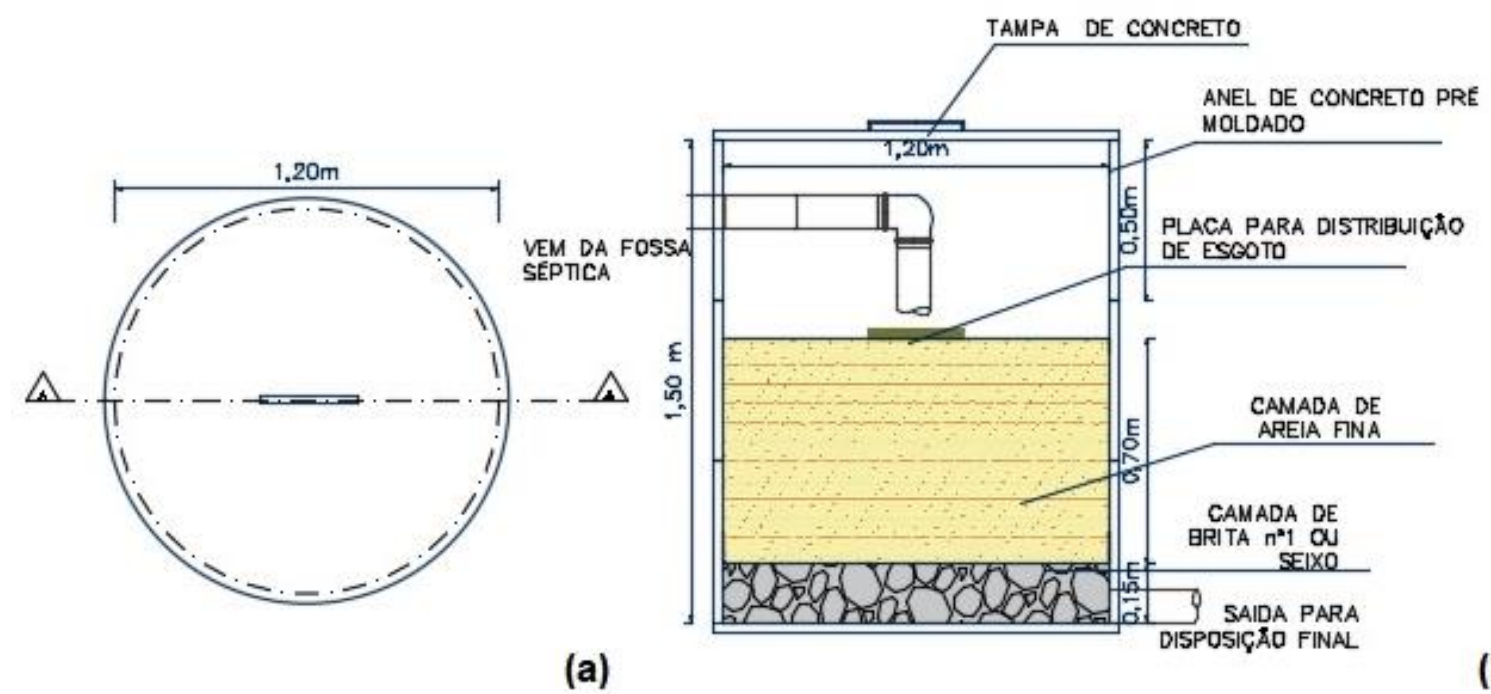

(b) 


\section{Comparação técnico-econômica entre as alternativas de tratamento estudadas}

O Quadro 2 retrata os dados estimados dos custos da implantação dos dois sistemas de tratamento porpostos neste trabalho. Tais custos foram estimados de acordo com o Sistema Nacional de Pesquisa de Custos e Índices (SINAPI) de 2019 para o estado de São Paulo. Em ambos os casos considerou-se que o esgoto passará por um filtro de areia após as alternativas de tratamento biológico testadas, com custo de $\mathrm{R} \$ 724,66$ (Quadro 2).

Quadro 2 - Síntese dos custos de implantação da fossa séptica e do biodigestor e filtro de areia.

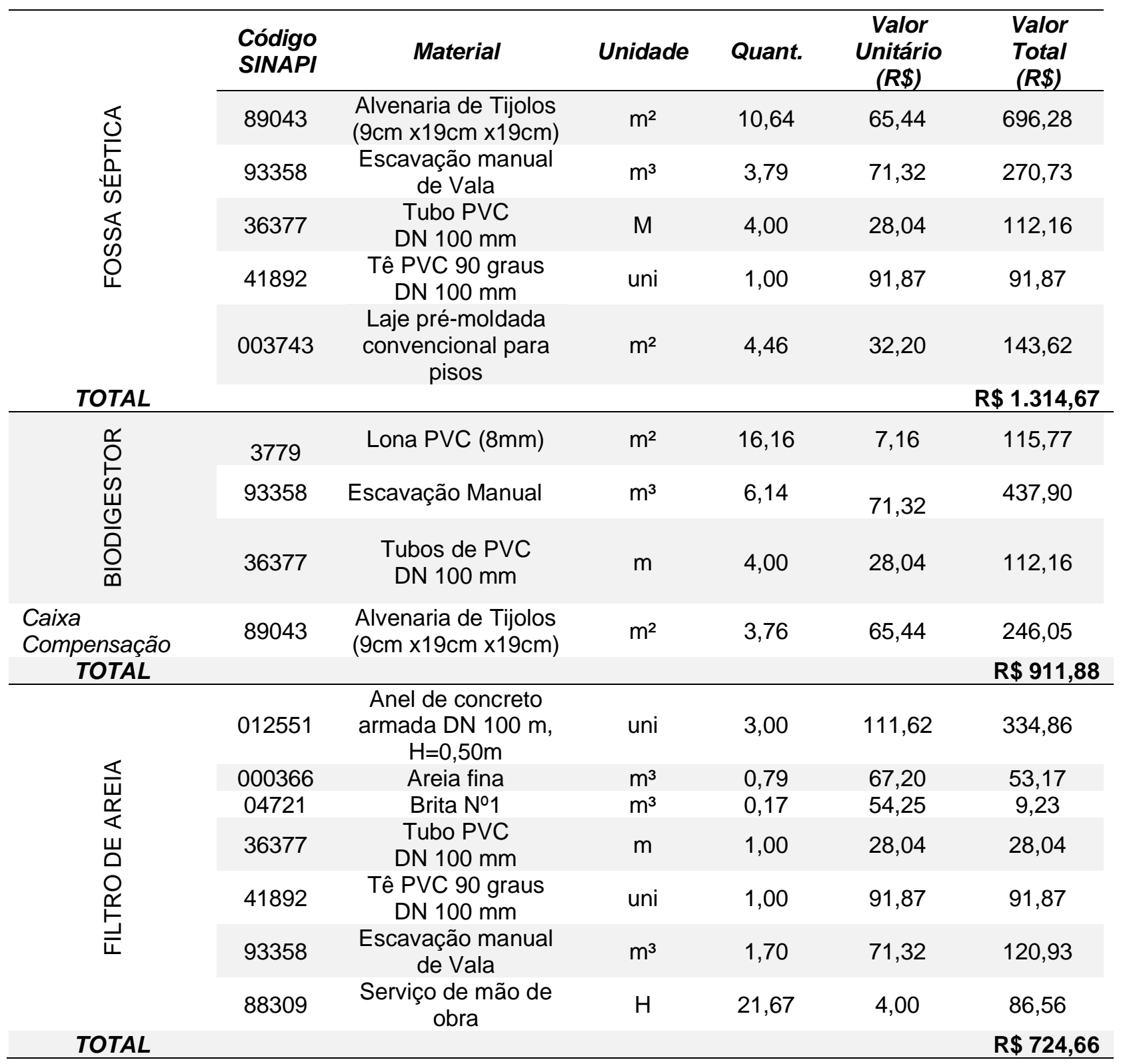

Os custos finais expostos no Quadro 2 evidenciam que a implantação do biodigestor 
Canadense $(R \$ 911,88)$ é mais vantajosa do que o tanque séptico $(R \$ 1.314,67)$. É imprescendível que seja feita a retirada do lodo de ambos sistemas de tratamento, conforme recomendações das normas perminentes. O acúmulo de lodo nesses sistemas, devido à falta de limpeza, pode ocasionar queda na eficiência de remoção de matéria orgânica, trazendo riscos à saúde de moradores e animais da propriedade rural, além de atrair insetos e roedores (TONETTI et al., 2018). A Tabela 8 retrata os resultados obtidos na estimativa de produção energética a partir do biogás produzido no biodigestor a partir das equivalências expostas na Tabela 3. Observa-se que, pelo fato do esgoto resultante das atividades humanas não ser muito concentrado, a produção potencial de energia elétrica foi marginal (Tabela 3). Caso outros rejeitos produzidos na propriedade fossem encaminhados para o tratamento, maior volume de biogas poderia ser produzido, resultando em índices de produção de GLP e energia elétrica mais significativos.

Tabela 8 - Produções diárias de biogás, GLP e energia elétrica considerando o volume de rejeitos produzidos na propriedade rural de estudo.

\begin{tabular}{lcccc}
\hline Tipo & Número & $\begin{array}{c}\text { Produção de } \\
\text { biogás } \\
\left(\mathrm{m}^{3} \mathrm{dia}^{-1}\right)\end{array}$ & $\begin{array}{c}\text { Produção } \\
\text { de GLP } \\
\left(\mathrm{Kg} \mathrm{dia}^{-1}\right)\end{array}$ & $\begin{array}{c}\text { Produção de } \\
\text { energia elétrica } \\
\left(\mathrm{Kwh} \mathrm{dia}^{-1}\right)\end{array}$ \\
\hline $\begin{array}{l}\text { Humano } \\
\text { Total }\end{array}$ & 3 & 0,03 & 0,00 & 0,03 \\
\hline
\end{tabular}

Fonte: Adaptado de BGS Equipamentos (2018).

\section{CONCLUSÕES}

As alternativas de tratamento decentralizado de esgoto sanitário estudadas no presente trabalho demonstraram ser tecnologias simples e de baixo custo. A partir do dimensionsionamento realizado e também das informações da literatura observou-se que, tanto a fossa séptica quanto o biodigestor, são tecnologias capazes de melhorar a qualidade sanitária em propriedades rurais e comunidades urbanas isoladas. $O$ biodigestor apresentou menor custo de implantação quando comparado ao tanque séptico. Além disso, destaca-se que, em caso de inserção de rejeitos produzidos pelos animais criados na propriedade ao tratamento do esgoto doméstico no biodigestor, seria possível potencializar os índices de produção de GLP e energia elétrica, impactando positivamente na viabilidade ecômica global desta configuração de tratamento.

\section{AGRADECIMENTOS}

Este trabalho recebeu o apoio financeiro do Programa Instituicional de Iniciação Científica PIBIC/UNIFIO (Núcleo de Pesquisa e Extensão, Processo nº 021-19).

\section{REFERÊNCIAS}

ASSOCIAÇÃO BRASILEIRA DE NORMAS TÉCNICAS. NBR 7229: Projeto, construção e operação de sistema de tanques sépticos. Rio de Janeiro, 1993.

. NBR 13969: Tanques sépticos; Unidades de tratamento complementar e disposição final dos efluentes líquidos - Projeto, construção e operação. Rio de Janeiro, 1997.

NBR 5626: Instalação predial de água fria. Técnicas. Rio de Janeiro,1996. 
RBCTI

1999.

NBR 8160: Instalações Prediais de esgoto sanitário - Procedimento. Rio de Janeiro,

ANDRADE, M.A.N.; RANZI, T.J.D.; MUNIZ, R.N.; SILVA, L.G.S.; ELIAS, M.J. Biodigestores rurais no contexto da atual crise de energia elétrica brasileira e na perspectiva da sustentabilidade ambiental.Universidade Federal de Santa Catarina. Florianópolis-SC,2002.

BGS. Cálculo de Produção de Biogás. 2018. Disponível em:

http://bgsequipamentos.com.br/blog/calculo-de-producao-de-biogás-2/. Acesso em: 22 mar. 2020.

BRASIL. Conselho Nacional de Meio Ambiente - CONAMA. Resolução CONAMA n. 357, de 17 de março de 2005. Dispõe sobre a classificação dos corpos de água e diretrizes ambientais para o seu enquadramento, bem como estabelece as condições e padrões de lançamento de efluentes, e dá outras providências. Disponível em:

http://www2.mma.gov.br/port/conama/legiabre.cfm?codlegi=459. Acesso em: 15 fev. 2019.

BRASIL. Conselho Nacional de Meio Ambiente - CONAMA. Resolução CONAMA n. 357, de 13

de maio de 2011. Dispõe sobre as condições e padrões de lançamento de efluentes, complementa e altera a Resolução no 357, de 17 de março de 2005, do Conselho Nacional do Meio Ambiente-CONAMA. Disponível em:

http://www2.mma.gov.br/port/conama/legiabre.cfm?codlegi=646. Acesso em: 15 fev. 2019.

BRASIL. Ministério do Desenvolvimento Regional. Secretaria Nacional de Saneamento - SNS.

Sistema Nacional de Informações sobre Saneamento: 24 Diagnóstico dos Serviços de Água e Esgotos - 2018. Brasília: SNS/MDR, 2019. 180 p.: il.

CONTERATO E.; STEIN, S. T.; ESPARTEL L.; ELTZ, M. K. F. Saneamento. 1. ed.: Porto Alegre: Sagah, 2018.

DEGANUTTI, R.; PALHACI, M. C. J. P.; ROSSI, M.; TAVARES, R.; DOS SANTOS C. Biodigestores rurais: modelo indiano, chinês e batelada. UNESP, Bauru, São Paulo.2002.

FUNASA. Ministério da Saúde. Fundação Nacional de Saúde. Manual do Saneamento. 4. ed. Brasília, 2015. 642 p.

INSTITUTO BRASILEIRO DE GEOGRAFIA E ESTATíSTICA. Pesquisa Nacional por Amostra de Domicílios (PNAD) 2013, volume 33. Rio de Janeiro: IBGE, 2013. 133 p.

INSTITUTO BRASILEIRO DE GEOGRAFIA E ESTATÍSTICA. Síntese de Indicadores Sociais: Uma análise das condições de vida população Brasileira, IBGE, 2018.

INSTITUTO BRASILEIRO DE GEOGRAFIA E ESTATÍSTICA.Panorama das Cidades. Disponivel em: https://cidades.ibge.gov.br/brasil/sp/sao-pedro-do-turvo/panorama. Acesso em: 10 fev. 2020.

KUNZ, A.; STEINMETZ, R. L. R.; AMARAL, A. C. Fundamentos da digestão anaeróbia, purificação, uso e tratamento do digestato: Sbera: Embrapa Suinos e Aves, Concórdia -SC, 2019.

LANDAU, E. C.; MOURA, L. Variação geográfica do saneamento básico no Brasil em 2010: domicílios urbanos e rurais. Brasília: Embrapa, 2016. 975 p. 
METCALF, L.; EDDY, H. P. Tratamento de Efluentes e Recuperação de Recursos. 5 ed, 2016. AMGH. Editora Ltda. Obra originalmente publicada sob o título Wastewater Engineering:

Treatment and Reuse, 5th Edition.

OLIVER, A. P. M; SOUZA NETO, A . A.; DE QUADROS, D. G.; VALLADADRES, R. E. Manual de treinamento em biodigestão. Instituto Winrock Brasil, p. 23, Salvador-Ba,2008.

RIBEIRO, D. S. Determinação das Dimensões de um Biodigestor em Função da Proporção Gás/fase Líquida. Revista Holos, v. 1, ano 27, 2011.

ROCHA, A. Histórias do Saneamento. 1. ed. São Paulo: Blucher, 2018.

TONETTI, A. L.; BRASIL, A. L.; MADRID, F. J. P. L.; FIGUEIREDO, I. C. S.; SCHNEIDER, J.; CRUZ, L. M. O. et al. Tratamento de esgotos domésticos em comunidades isoladas: referencial para a escolha de soluções. Biblioteca Unicamp: Campinas, 2018. 